UDC 811.112.2'42

Submitted: 01.02.2017

LBC 81.432.4-51

Accepted: 15.05.2017

\title{
STRUCTURAL-SEMANTIC FEATURES AND PRAGMALINGUISTIC POTENTIAL OF TEASING RHYMES IN GERMAN JUNIOR SCHOOLCHILD'S DISCOURSE
}

\author{
Galina A. Lebedenko \\ Pyatigorsk State University, Pyatigorsk, Russian Federation
}

\section{Galina G. Matveeva}

Don State Technical University, Rostov-on-Don, Russian Federation

\begin{abstract}
The paper deals with several types of teasing rhyme structure: two-component rhymed utterances that consist of a person nomination and a rhyming element, rhymed utterances with an attributively modifying word combination; teasing rhymes as a complex structure texts. It is pointed out that the rhymed component is based on assessment of personality or a person's name, teasing rhymes may be based on pejorative names that are regularly directed to an addressee. They are specified with humor tone and play on words; they are used with the aim to ridicule names, appearance, traits of character or behavior of a child. The teasing rhyme as a unit of functional pragmalinguistics is viewed as a vocative that helps in self-presentation in the German junior schoolchild's discourse.

The authors state that the choice of a certain type of the teasing rhyme depends on a number of circumstances: communicative situation, relationship between speakers, and communicative purpose of speech. The analysis of teasing rhyme demonstrated some regulations: while choosing semantic fillers a child might address to the following communicative tactics in accessing the communicative strategy of self-presentation: the tactics that demonstrates self-belonging to a group or the tactics of the addressee humiliation.

The results of research enable to conclude that teasing rhymes reflect interpersonal relations of junior schoolchildren at school and in the family, they may be viewed as verbal means that set social norms of life for children.

Key words: teasing rhymes, forms of address, discourse, junior schoolchild, communicative purpos, selfpresentation, communicative strategy, communicative tactics.

Citation. Lebedenko G.A., Matveeva G.G. Structural-Semantic Features and Pragmalinguistic Potential of Teasing Rhymes in German Junior Schoolchild's Discourse. Vestnik Volgogradskogo gosudarstvennogo universiteta. Serija 2, Jazykoznanije [Science Journal of Volgograd State University. Linguistics], 2017, vol. 16, no. 2, pp. 152-159. (in Russian). DOI: https://doi.org/10.15688/jvolsu2.2017.2.16.
\end{abstract}

\section{СТРУКТУРНО-СЕМАНТИЧЕСКИЕ ОСОБЕННОСТИ И ПРАГМАЛИНГВИСТИЧЕСКИЙ ПОТЕНЦИАЛ ДРАЗНИЛОК В ДИСКУРСЕ НЕМЕЦКОГО МЛАДШЕГО ШКОЛЬНИКА}

\author{
Галина Александровна Лебеденко \\ Пятигорский государственный университет, г. Пятигорск, Российская Федерация
}

Галина Григорьевна Матвеева

Донской государственный технический университет, г. Ростов-на-Дону, Российская Федерация

Аннотация. В статье рассмотрено несколько типов структурного построения дразнилок: двухкомпонентные выражения, состоящие из обозначения лица и рифмующегося компонента; рифмованные выраже- 
ния, дополнительно распространенные атрибутивным словосочетанием; дразнилки, представляющие собой тексты более сложной структуры. Показано, что рифмующийся компонент может выражать оценку лица или его имени; в качестве дразнилки могут выступать пейоративные номинации, регулярно используемые в отношении конкретного адресата; дразнилки обладают игровой юмористической тональностью; предметом осмеяния в них выступают имя, внешность, характер, поведение ребенка.

Обращение-дразнилка в аспекте функциональной прагмалингвистики рассмотрено как средство реализации коммуникативной стратегии самопрезентации в дискурсивной деятельности немецких младших школьников.

Установлено, что выбор младшим школьником той или иной дразнилки находится в зависимости от составляющих речевого акта: ситуации общения, отношений между коммуникантами, коммуникативной цели высказывания. Изучение осознаваемого адресантом выбора лексических единиц позволило выявить в рамках коммуникативной стратегии самопрезентации две коммуникативные тактики, реализованные в речи немецкого младшего школьника посредством дразнилки: тактику выражения принадлежности к группе «своих» и тактику уничижения адресата. Показано, что дразнилки отражают межличностные отношения младших школьников в школе и семье, а также выступают вербальным регулятивным средством, с помощью которого утверждаются нормы (в том числе речевые) коллективной жизни детей.

Ключевые слова: дразнилка, обращение, дискурс, младший школьный возраст, коммуникативная цель, самопрезентация, коммуникативная стратегия, коммуникативная тактика.

Цитирование. Лебеденко Г. А., Матвеева Г. Г. Структурно-семантические особенности и прагмалингвистический потенциал дразнилок в дискурсе немецкого младшего школьника // Вестник Волгоградского государственного университета. Серия 2, Языкознание. - 2017. - Т. 16, № 2. - C. 152-159. - DOI: https://doi.org/ 10.15688/jvolsu2.2017.2.16.

\section{1. Введение}

В современной лингвистике сохраняется устойчивый интерес к прагмалингвистическим особенностям речи представителей различных социальных групп (см., например: [Матвеева, Акулова, 2016; Тактарова, Матвеева, 2014; Kiesendahl, 2011]), в том числе особенностей речи младших школьников (например: [Амзаракова, 2014; Стернин, Лемяскина, 2000]). Однако недостаточно изученным остается вопрос о дразнилке как элементе немецкоязычного детского и школьного дискурсов, хотя именно этот жанр формирует специфику детского межличностного общения.

Мир детства можно рассматривать как особое измерение, которое характеризуется специфическими свойствами восприятия и познания социального пространства. Это своеобразные способы конструирования и использования языка и культурного окружения, в котором воспитывается ребенок [Лебеденко, 2016, с. 104]. Неотьемлемой составляющей мира детства являются дразнилки. Они позволяют ребенку адаптироваться к новым социальным условиям школьной жизни, в частности, посредством принятого в детской среде способа выраже- ния отрицательных эмоций. При этом важное место продолжает занимать языковая игра, одним из приемов которой в детской речи выступает дразнилка.

Материалом исследования послужили результаты анкетирования и интервью, проведенных с носителями языка - немецкоязычными детьми младшего школьного возраста, а также собственные наблюдения автора. Респондентами выступили 85 детей в возрасте 7-11 лет, проживающие в г. Берлин и других городах земли Бранденбург (Германия) и обучающиеся в различных образовательных учреждениях на начальной ступени. Общая длительность записей интервью составляет 7 часов. Всего было зафиксировано и проанализировано 97 эпизодов с использованием немецких дразнилок.

\section{2. Структурно-семантическая}

\section{характеристика немецких дразнилок}

По форме дразнилки представляют собой краткие поэтические высказывания юмористического, реже сатирического характеpa [Капица, Колядич, 2002, с. 85]. В нашем материале в большинстве случаев они имеют двухкомпонентную структуру (52 эпизода): на первом месте находится обозначение 
лица, на втором - рифмующийся компонент, выражающий оценку данного лица или его имени: Lothar Kothar; Frerk-Zwerg (в приведенных примерах первый компонент выражен именем собственным). Эти двухкомпонентные образования могут быть дополнительно распространены атрибутивным словосочетанием: Lene-Pompene mit den krummen Beenen (пример иронического обращения к девочке по имени Лена с ногами «колесом»). Дразнилка также может представлять собой рифмованный текст более сложной структуры (22 эпизода):

Kathrin, Katherein,

was machen deine Schwein,

sind sie fett, sind sie mager,

oder sind sie wie du: so hager?

В приведенном тексте отражена миниситуация: «Катрин, Катерина, что делают твои свиньи? Жирные они или худые, или такие же тощие, как ты?» (здесь и далее перевод дразнилок наш. - Г. Л., Г. М.). Повторяющиеся элементы (Katherein - Schwein, mager hager) способствуют эмфатическому акцентированию семантики слов, частью которых они являются, и связывают все фрагменты текста дразнилки в единое целое (о функциях повтора см.: [Устина, Устин, 2013, с. 53]).

В речи младшего школьника функцию дразнилки выполняют не только рифмованные структуры, но и пейоративные номинации (26 эпизодов), регулярно используемые адресантом по отношению к конкретному адресату, например: Du Esel, Du Schwein.

Основания для образования дразнилок могут быть различными: имя (49 эпизодов): Basti-Spasti, Klaus-blaue Maus; внешность (21 эпизод): halbe Portion - по отношению к худенькой девочке, Spargeltarzan - о субтильном мальчике; характер (16 эпизодов): Heiner, der Weiner, den mag keiner - о мальчике-плаксе; интеллектуальные способности (11 эпизодов): Inge, widwinge, widewilka, matum, die Inge ist dumm.

Итак, дразнилки, используемые в речи немецкоязычными младшими школьниками, представляют собой, как правило, рифмованные тексты различной сложности или одиночные наименования, отражающие разные основания для высмеивания.

\section{3. Прагматическая характеристика дразнилки}

Основная цель употребления дразнилки в речи - высмеять собеседника, что часто способствует возникновению ссор между детьми. Однако эти конфликтные речевые события естественны, являются составляющими процесса социализации ребенка младшего школьного возраста: демонстрируют постепенное становление коммуникативной личности, овладевающей коммуникативными стратегиями и тактиками в различных ситуациях.

Речевая деятельность школьника исследуется нами в рамках дискурса, который, вслед за Н.Д. Арутюновой, определяется в данной статье как связный текст в совокупности с экстралингвистическими факторами, то есть как речь, «погруженная в жизнь» [Арутюнова, 1990, с. 136]. В работе рассматривается дискурс младшего школьника, представляющий собой тип дискурса, который выделяется по возрастному и социальному критерию (от 7-8 до 10-11 лет) и отражает особенности детского мышления (подробно о специфике ментальной деятельности ребенка см.: [Моргунова, 2013, с. 86]).

Единицей анализа в нашем исследовании послужила реализация обращений-дразнилок в речи немецкого младшего школьника. Анализ осуществляется с использованием приемов прагмалингвистики - дисциплины современного языкознания, одним из направлений которой является изучение выбора отправителем текста оптимальных речевых единиц из набора равнозначных для достижения наилучшего воздействия на получателя текста [Степанов, 1981, с. 325-326]. Исследование, результаты которого представлены в статье, выполнено в рамках функциональной прагмалингвистики, то есть анализируется продуманный и осознаваемый отправителем выбор единиц речи для достижения коммуникативной цели высказывания [Матвеева, Самарина, Селиверстова, 2009, с. 51]. Употребление дразнилок в речи младшего школьника является осознанным и мотивированным.

В младшем школьном возрасте ребенок уже знает, что один и тот же объект может иметь несколько имен в зависимости от ситу- 
ации. Ему также известна воздействующая сила имени, а именно тот факт, что с помощью имени можно выразить симпатию, недовольство или оценить собеседника.

При анализе прагмалингвистических характеристик эпизодов с дразнилками нами учитываются такие составляющие речевого акта, как адресат и адресант и их взаимоотношения, речевой жанр, тема, контекст и ситуация [Хаймс, 1975].

По своей форме и функции дразнилки являются речевым жанром детского фольклора и представляют собой текст, который используется младшими школьниками (адресантами) по отношению к адресатам-ровесникам, детям старшего или младшего возраста. Чаще дразнят тех, кто не отличается силой, привлекательностью или сообразительностью. Дразнилки встречаются в речи ребенка в полуофициальных ситуациях общения в школе, в неофициальных ситуациях в семье, вне школы при общении с друзьями и недругами.

Обращения-дразнилки использованы в речи младших школьников при реализации стратегии самопрезентации. Она определяется как процесс управления говорящим производимым впечатлением с целью контролирования поведения других людей и их ответной реакции на производимые действия [Гофман, 2000]. Данная стратегия является ведущей коммуникативной стратегией в речевом поведении детей младшего школьного возраста, что соответствует интеграции ребенка в общество и связанной с этим социализацией в новых условиях школы.

Стратегия самопрезентации реализуется посредством тактики выражения принадлежности к группе «своих» и тактики уничижения адресата.

3.1. Тактика выражения принадлежности к группе «своих» реализуется в полуофициальных ситуациях общения со сверстниками в школе и в неофициальных ситуациях общения в кругу друзей и в семье. Данная тактика направлена на подчеркивание коммуникантами общности взглядов и интересов в рамках данной группы.

Дразнилка выступает регулятивным средством, при помощи которого утверждаются нормы коллективной жизни детей и по- рицается нежелательное для группы поведение. Таким образом, дразнилки являются своеобразными предписаниями, что следует и чего не следует делать для того, чтобы с ребенком общался коллектив, группа «своих».

В рамках тактики выражения принадлежности к группе «своих» использование дразнилки в речи подчеркивает неофициальность, некоторую интимность коммуникативной ситуации. Дразнилка употребляется только по отношению к конкретному адресату, а цель ее использования - не обидеть адресата, а лишь подшутить над ним. Подшучивание распространено в речи детей младшего школьного возраста, оценивается ими как безобидное поведение и является одним из способов выражения детского юмора (подробнее о юморе в речи детей см.: [Kotthoff, 2003]).

Для подшучивания школьник использует ироничные, порой абсурдные дразнилки, образованные от имени собственного с созвучным рифмованным дополнением. Например: Christian-Wüstelmann! Komm, wir schieben noch ein paar Elfer! Эта дразнилка использована мальчиком 9 лет по отношению к его другу. Собеседники являются ровесниками. Дразнилка ChristianWüstelmann, образованная от имени собственного добавлением рифмующего компонента, употребляется в речи не с целью обидеть собеседника; это безобидная шутка, которая представляется ребенку просто смешной и интересной.

Обращение, выраженное дразнилкой, может быть также иронично использовано для побуждения адресата к более интенсивному совершению действия: Du, Humpelpumpel, was machst du denn! Wir verlieren doch! Эта дразнилка употреблена в ситуации, когда изза медлительных действий одного из детей на уроке спорта вся команда проигрывает. Рифмованное обращение-антропоним, производное от имени сказочного персонажа (старичка-гнома), выражает упрек с оттенком иронии и использовано с целью подшутить над адресатом, стимулировать его играть лучше.

Дразнилки, выраженные обозначением животного, также часто употребляются в детской речи с целью поторопить адресата, например: обращение Schnell, schnell, Frau 
Kamel! по отношению к медлительной девочке 7 лет. Взрослый носитель немецкого языка ассоциирует верблюда (Kamel) с глупостью; одним из значений слова Kamel является значение «Dummkopf», «Trottel» (дурак, простофиля), что зафиксировано в словаре Duden. Однако в речи ребенка (девочка 9 лет) данное обращение-дразнилка имеет целью поторопить подружку. В аналогичных этой ситуациях детьми используются высказывания с обращениями Du lahme Schnecke! (признак медлительности приписывается улитке), $D u$ lahme Ente! Wird's bald? (тот же признак приписывается утке).

В качестве дразнилки может быть использовано имя собственное, которое не нравится адресату. Опрошенными нами детьми-респондентами были описаны ситуации, в которых имя могло совпадать с кличкой животного, было старомодным или комичным по звучанию. Употребление в речи субъекта коммуникации такого имени собственного по отношению к коммуниканту выполняет функцию дразнилки. Так, например, в речи одного из респондентов краткая форма имени собственного Leo (от Leon) употребляется как дразнилка по отношению к старшему брату. Поскольку Leo в этой же семье - кличка кота, использование ее в дразнилке акцентирует принадлежность говорящего к конкретной семье.

В одном из проведенных интервью девочка 6 лет сообщает о том, что просит членов своей семьи не обращаться к ней по имени (Nella), так как считает его комичным, а в среде сверстников оно стало объектом иронии и основанием для образования дразнилок (Nella-Propella).

3.2. Тактика уничижения адресата направлена на самоутверждение ребенка младшего школьного возраста путем подчеркивания каких-либо отрицательных качеств получателя сообщения.

Дразнилка в качестве обращения является наиболее распространенным средством уничижения. Цель сообщения в таких ситуациях - обидеть и высмеять собеседника, в частности, указанием на излишний или недостаточный вес, особенности роста, поведения.

Например, дразнилка в речи мальчика 10 лет (Ziehst du Arm und Beine ein, könntest $d u$ 'eine Kugel sein - если втянешь руки и ноги, станешь похожим на шар) обращена к ребенку, имеющему лишний вес, она указывает на недостаток внешности, полноту, округлую форму тела.

В рамках тактики уничижения адресата детьми часто используются дразнилки со сниженной коннотацией. Так, мальчик 11 лет в неофициальной ситуации на перемене в школе обращается к худенькой девочке-ровеснице: Ilse, Du siehst aus, wie ein Schnittchen, kein Arsch und kein Tittchen. Такая грубая дразнилка используется для обращения и высмеивания худенькой девочки, у которой «ни груди, ни попы».

Дразнилки могут выступать средством вербальной защиты в ситуации ссоры между детьми и принимать форму своеобразной словесной «дуэли» младших школьников. В таком случае дразнилка представляет собой не только обращение, но и полноценное высказывание, самостоятельный акт речи. Например:

- Heiner, der Weiner, den mag keiner!

- Annete, die Fette, sitzt auf der Toilette!

В приведенном примере коммуникантами являются девочка 8 лет и ее одноклассник - мальчик того же возраста. Из контекста мы знаем, что Хайнер - очень обидчивый и плаксивый ребенок, Аннете хочет принизить и высмеять его, подчеркивая в обращении его отрицательное качество (плакса). Однако ответной реакцией становится обращение-дразнилка, адресованная девочке. В обеих репликах дети используют речевые единицы, обозначающие негативно оцениваемые в детской среде объекты (Weiner, Fette, Toilette).

Типичной реакцией на дразнилку является «антидразнилка». Подобные фразы - это своеобразная защита от словесного нападения, которая дает возможность ребенку справиться с чувством неловкости в условиях, когда он не знает, как правильно отреагировать на пренебрежительное отношение. Цель таких высказываний - посрамить собеседника словом: Selber, selber, lacht die blöde Kuh, und die bist du! или Selber, selber lachen alle Kälber! (В русскоязычной детской среде существуют аналогичные дразнилки: Kто обзы- 
вается, тот сам так называется; Сам дурак и т. д.).

Прагматический потенциал дразнилок раскрывается в их целенаправленном употреблении для реализации ребенком конкретных намерений в рамках коммуникативных стратегий и тактик. Ребенок младшего школьного возраста использует обращения-дразнилки в рамках стратегии самопрезентации, которая реализуется посредством тактики выражения принадлежности к группе «своих» и тактики уничижения адресата. С помощью дразнилки младший школьник подшучивает над собеседником, побуждает его к дальнейшему действию. Дразнилки выступают средством уничижения, а также используются в качестве защитной реакции на словесное нападение.

\section{4. Выводы}

Обращения-дразнилки, используемые в речи немецкими младшими школьниками, могут быть различными по структуре и обладать разнообразной палитрой значений. Дразнилки представляют собой как двухкомпонентные высказывания, так и рифмованные тексты более сложной структуры. Часто дразнилки основаны на игре слов и являются выражением детского юмора.

Прагмалингвистический анализ дразнилок в речи немецкого младшего школьника показал, что они, отражая межличностные отношения младших школьников в школе и семье, становятся неотъемлемой частью коммуникации детей в возрасте 7-11 лет. Обращения-дразнилки использованы в речи немецких младших школьников при реализации стратегии самопрезентации, в основе которой лежат две выделенные нами тактики: тактика выражения принадлежности к группе «своих» и тактика уничижения адресата. Употребляя в речи дразнилки, дети выражают свои негативные эмоции, учатся разрешать конфликтные ситуации, а также понимать и использовать в речи воздействующую силу слова, его прагмалингвистический потенциал. Он заключается в намеренном и осознаваемом употреблении ребенком дразнилки для осуществления своих интенций: явных или скрытых целей общения (под- шучивание, побуждение к действию, уничижение, высмеивание, защитная ответная реакция).

Богатство эмпирического материала позволяет продолжить исследование в разных направлениях, в частности он дает возможность выявить лингвокультурологическую специфику дразнилок.

\section{СПИСОК ЛИТЕРАТУРЫ}

Амзаракова, И. П. Проблемы и перспективы изучения детской речи / И. П. Амзаракова // Вестник Хакасского государственного университета им. Н.Ф. Катанова. - 2014. - № 7. - С. 12-16.

Арутюнова, Н. Д. Дискурс / Н. Д. Арутюнова // Лингвистический энциклопедический словарь / гл. ред. В. Н. Ярцева. - М. : Советская энциклопедия, 1990.- С. 136-137.

Гофман, И. Представление себя другим в повседневной жизни / пер. с англ. и вступ. ст. А. Д. Ковалева. М. : КАНОН-пресс-Ц, 2000.-304 с.

Капица, Ф. С. Русский детский фольклор / Ф. С. Капица, Т. М. Колядич. - М. : Флинта : Наука, 2002. $-320 \mathrm{c}$.

Лебеденко, Г. А. К вопросу изучения детской речи в России и Германии / Г. А. Лебеденко // Филологические науки. Вопросы теории и практики. 2016. - № 2 (56), ч. 2. - C. 104-108.

Матвеева, Г. Г. Два направления в современной прагмалингвистике / Г. Г. Матвеева, И. В. Самарина, Л. Н. Селиверстова // Вестник Санкт-Петербургского университета. Серия 12, Психология. Социология. Педагогика. -2009 . - № 1-2. - С. 50-57.

Матвеева, Г. Г. Особенности речевого поведения носителей молодежного мультиэтнолекта Kiezdeutsch (прагмалингвистический аспект) / Г. Г. Матвеева, М. Е. Акулова // Политическая лингвистика. - 2016. - № 1 (55). - С. 136-143.

Моргунова, Л. А. Детский дискурс: репрезентация специфики детского мышления / Л. А. Моргунова // Известия Южного федерального университета. Филологические науки. - 2013. - № 1. - С. 86-92.

Степанов, Ю. С. В поисках прагматики (проблема субъекта) / Ю. С. Степанов // Известия АН СССР. Серия литературы и языка. - 1981. - Т. 40, № 4. - C. 325-332.

Стернин, И. А. Коммуникативное поведение младшего школьника / И. А. Стернин, Н. А. Лемяскина. - Воронеж : [б. и.], 2000. - 201 с.

Тактарова, А. В. Речевые привычки журналиста на примере стратегии «акцентуация автором элементов речевого события» / А. В. Тактарова, Г. Г. Матвеева // Вестник Волжского университета им. В.Н. Татищева. -2014. - № 4 (17). - С. 252-258. 
Устина, Н. В. Синергетика повтора как энергия смыслового структурирования текста / Н. А. Устина, А. К. Устин. - Пятигорск : ПГЛУ, 2013. - 134 с.

Хаймс, Д. Х. Этнография речи / Д. Х. Хаймс // Новое в лингвистике. Вып. VII : Социолингвистика. - М. : Прогресс, 1975. - С. 42-95.

Kiesendahl, J. Status und Kommunikation: Ein Vergleich von Sprechhandlungen in universitären E-Mails und Sprechstundengesprächen / J. Kiesendahl. - Berlin : Erich Schmidt Verlag, 2011. - 393 S.

Kotthoff, H. Witz komm raus! Komik und Humor bei Kindern: ein Überblick / H. Kotthoff // TELEVIZION. - 2003. - № 1 (16). -S. 4-11.

\section{REFERENCES}

Amzarakova I.P. Problemy i perspektivy izucheniya detskoy rechi [The Issues and Trends in the Study of Childrens Speech]. Vestnik Khakasskogo gosudarstvennogo universiteta im. N.F. Katanova, 2014, no. 7, pp. 12-16.

Arutyunova N.D. Diskurs [Discourse]. Yartseva V.N., ed. Lingvisticheskiy entsiklopedicheskiy slovar [Linguistic Encyclopedic Dictionary]. Moscow, Sovetskaya entsiklopediyaPubl., 1990, pp. 136-137.

Goffman E. Predstavlenie sebya drugim v povsednevnoy zhizni [Self-Presentation in Everyday Life]. Moscow, KANON-press-C Publ., 2000. 304 p.

Kapitsa F.S., Kolyadich T.M. Russkiy detskiy folklor [Russian Children's Folklore]. Moscow, Flinta; Nauka Publ., 2002. 320 p.

Lebedenko G.A. K voprosu izucheniya detskoy rechi v Rossii i Germanii [On the Problem of Childrens Speech Studies in Russia and Germany]. Filologicheskie nauki. Voprosy teorii i praktiki, 2016, no. 2 (56), part 2, pp. 104-108.

Matveeva G.G., Samarina I.V., Seliverstova L.N. Dva napravleniya $\mathrm{v}$ sovremennoy pragmalingvistike [Two Directions in the Modern Pragmalinguistics]. Vestnik SanktPeterburgskogo universiteta. Seriya 12, Psikhologiya. Sotsiologiya. Pedagogika, 2009, no. 1-2, pp. 50-57.

Matveeva G.G., Akulova M.E. Osobennosti rechevogo povedeniya nositeley molodezhnogo multietnolekta Kiezdeutsch (pragmalingvisticheskiy aspekt) [Peciliarities of Verbal Behavior of Kiezdeutsch Speakers (Pragmalinguistic Aspect)]. Politicheskaya lingvistika, 2016, no. 1 (55), pp. 136-143.

Morgunova L.A. Detskiy diskurs: reprezentatsiya spetsifiki detskogo myshleniya [Childrens Discourse: Representation of Specificity of Childrens Cogitation]. Izvestiya Yuzhnogo federalnogo universiteta. Filologicheskie nauki, 2013, no. 1, pp. 86-92.

Stepanov Yu.S. V poiskakh pragmatiki (problema subyekta) [In Search of Pragmatics (the Issue of the Subject)]. Izvestiya AN SSSR. Seriya literatury $i$ yazyka, 1981, vol. 40, no. 4, pp. 325-332.

Sternin I.A., Lemyaskina N.A. Kommunikativnoe povedenie mladshego shkolnika [Communicative Behavior of a Junior Schoolchild]. Voronezh, 2000. $201 \mathrm{p}$.

Taktarova A.V., Matveeva G.G. Rechevye privychki zhurnalista na primere strategii «aktsentuatsiya avtorom elementov rechevogo sobytiya» [Verbal Habits of Journalist as Exemplified in the Stratedy "Authors Accentuation in Elements of Speech Event"]. Vestnik Volzhskogo universiteta im. V.N. Tatishcheva, 2014, no. 4 (17), pp. 252-258.

Ustina N.V., Ustin A.K. Sinergetika povtora kak energiya smyslovogo strukturirovaniya teksta [Synergetics of Repetition as the Energy of the Notional Structuring of the Text]. Pyatigorsk, PGLU Publ., 2013. 134 p.

Hajms D.H. Etnografiya rechi [The Ethnography of Communication]. Novoe v lingvistike. Vyp. VII : Sotsiolingvistika [The New in Linguistics. Iss. 7: Sociolinguistics]. Moscow, Progress Publ., 1975, pp. 42-95.

Kiesendahl J. Status und Kommunikation: Ein Vergleich von Sprechhandlungen in universitären EMails und Sprechstundengesprächen [Status and Communication: A Comparison of Speech Actions in University E-mails and Speech Hour Talks]. Berlin, Erich Schmidt Verlag, 2011.393 p.

KotthoffH. Witz komm raus! Komik und Humor bei Kindern: ein Überblick [Joke Come out! Comic and Humor with Children: an Overview]. TELEVIZION, 2003, no. 1 (16), pp. 4-11. 


\section{Information About the Authors}

Galina A. Lebedenko, Postgraduate Student, Lecturer, Department of Germanic Studies and Intercultural Communication, Pyatigorsk State University, Prosp. Kalinina, 9, 357532 Pyatigorsk, Russian Federation, g-lebedenko@mail.ru, http://orcid.org/0000-0002-0282-2652.

Galina G. Matveeva, Doctor of Sciences (Philology), Professor, Department of World Languages and Cultures, Don State Technical University, Gagarina St., 1, 344002 Rostov-on-Don, Russian Federation, gegemat2337633@rambler.ru, http://orcid.org/0000-0002-6407-4274.

\section{Информация об авторах}

Галина Александровна Лебеденко, аспирант, преподаватель кафедры германистики и межкультурной коммуникации, Пятигорский государственный университет, просп. Калинина, 9, 357532 г. Пятигорск, Российская Федерация, g-lebedenko@mail.ru, http://orcid.org/0000-0002-02822652.

Галина Григорьевна Матвеева, доктор филологических наук, профессор кафедры мировых языков и культур, Донской государственный технический университет, пл. Гагарина, 1, 344002 г. Ростов-на-Дону, Российская Федерация, gegemat2337633@rambler.ru, http://orcid.org/0000-00026407-4274. 